\title{
GAMBARAN FUNGSI EKSEKUTIF PADA PASIEN POST STROKE MENGGUNAKAN PEMERIKSAAN CLOCK DRAWING TEST (CDT) DI POLI NEUROLOGI RSUP PROF. DR. R. D KANDOU PERIODE NOVEMBER-DESEMBER 2014
}

\author{
${ }^{1}$ Afrilya N. Solang \\ ${ }^{2}$ J. Maja P. S \\ ${ }^{2}$ Danny J. Ngantung
}

\author{
${ }^{1}$ Kandidat Skripsi Fakultas Kedokteran Universitas Sam Ratulangi Manado \\ ${ }^{2}$ Bagian Neurologi Fakultas Kedokteran Universitas Sam Ratulangi Manado \\ Email: lhyasolang@gmail.com
}

\begin{abstract}
Approximately 50-75\% of stroke patients is estimated to have impaired cognitive function. One of the components of cognitive function impaired is executive function. Clock drawing test (CDT) is one of the screening tools that are used to determine the executive functions of the brain. This study aimed to obtain the description of executive function in poststroke patients in Neurology Clinic of Prof. Dr. R. D. Kandou Hospital. This was a descriptive study using cross-sectional design. This study was carried out within a certain period between November to December 2014. The CDT showed 2 people were normal and 28 people were abnormal. Both male and female groups showed one person normal and 14 people abnormal. Based on the age group, 51-65 years old was the most vulnerable age with one normal person and 16 people were abnormal. Based on the education, most of them were in senior high school or equivalent with one person normal and 12 people were abnormal. Based on the jobs, retirees were the most vulnerable with 9 abnormal people. Based on the location of brain lesions, 17 people had lesions in the right hemisphere and 13 people had lesions in the left hemisphere. Based on the type of stroke, 29 people had ischemic stroke and 1 person had hemorrhagic stroke. Conclusion: Based on the CDT, the majority of respondents experienced impaired cognitive function, especially the executive function .
\end{abstract}

Keywords: stroke, cognitive function, executive function, clock drawing test

\begin{abstract}
Abstrak: Sekitar 50-75\% pasien dengan riwayat stroke diperkirakan mengalami gangguan fungsi kognitif; salah satunya ialah fungsi eksekutif. Tes menggambar jam adalah salah satu pemeriksaan yang digunakan untuk mengetahui fungsi eksekutif otak yang mengalami kemunduran. Penelitian ini bertujuan untuk mengetahui gambaran fungsi eksekutif pada pasien post stroke di Poli Neurologi BLU RSUP Prof. Dr. R. D. Kandou. Penelitian ini bersifat deskriptif dengan menggunakan desain potong lintang. Penelitian dilakukan di antara bulan November dan Desember 2014. Sampel yang memenuhi kriteria yang berjumlah 30 orang (15 laki-laki dan 15 perempuan). Dari hasil pemeriksaan tes menggambar jam didapatkan 2 orang normal dan 28 orang abnormal. Dari jenis kelamin baik laki-laki maupun perempuoan diperoleh 1 orang normal dan 14 lainnya abnormal. Dari golongan usia, terbanyak pada usia 51-65 tahun yaitu 1 orang normal dan 16 orang abnormal. Dari tingkat pendidikan, terbanyak pada tingkat SMA/Sederajat dengan 1 orang normal dan 12 orang abnormal. Dari pekerjaan, pensiunan merupakan yang terbanyak yaitu 9 orang abnormal. Dari letak lesi otak, 17 orang dengan letak lesi pada hemisfer kanan dan 13 orang yang mengalami lesi di daerah hemisfer kiri. Dari jenis stroke, lebih banyak yang mengalami stroke iskemik yaitu 29 orang dibandingkan yang mengalami stroke hemoragik yaitu 1 orang. Simpulan: Dari hasil
\end{abstract}


pemeriksaan CDT, sebagian besar responden (93,3 \%) mengalami gangguan kognitif lebih khusus gangguan eksekutif.

Kata kunci: stroke, fungsi kognitif, fungsi eksekutif dan tes gambar jam.

Stroke adalah serangan mendadak yang terjadi pada pembuluh darah otak di sebabkan oleh tersumbatnya atau pecahnya pembuluh darah dalam otak, selain itu stroke juga merupakan penyakit neurologik (saraf) yang sering menyebabkan kecacatan dan kematian sehingga dapat juga di sebut sebagai brain attack atau serangan otak. ${ }^{1}$

Setiap tahun, kurang lebih 15 juta orang di seluruh dunia terserang stroke.Di Amerika Serikat sekitar 5 juta orang pernah mengalami stroke, sedangkan di Inggris sekitar 250.000 orang. Di Indonesia, stroke menyerang 35,8 \% pasien usia lanjut dan $12,9 \%$ pada usia yang lebih muda. Jumlah total pasien stroke di Indonesia diperkirakan 500.000 setiap tahun. Dari jumlah itu, sekitar 2,5\% atau 250.000 orang meninggal dunia, dan sisanya cacat ringan maupun berat. Insiden stroke di seluruh dunia bervariasi. Insidens tahunan rata- rata meningkat sejalan dengan pertambahan usia, dari 3 per 100.000 pada kelompok usia dekade ketiga dan keempat menjadi hampir 300 per 100.000 penduduk pada kelompok usia dekade kedelapan dan kesembilan. $^{2}$

Pada pasien stroke 60,7 persen disebabkan oleh stroke non hemoragik sedangkan 36,6 persen oleh karena stroke hemoragik. Stroke trombotik paling banyak terdapat $(58,3 \%)$, disusul oleh perdarahan intraserebral (PIS) (35,6\%). Emboli dan perdarahan subaraknoidal hanya sedikit sekali 2,4\% dan 1 \%. Laki-laki (63,5\%) lebih banyak terkena dari pada wanita (36,5\%). Usia kurang dari 45 tahun lebih jarang terkena $(15,9 \%)$ dan pada usia lebih dari 45 tahun (84,1\%). Kematian dan seluruh stroke $(32,1 \%)$ adalah nomer dua setelah meningoensefalitis (59,5\%). Dari semua pasien stroke $50 \%$ dan PIS meninggal, sedangkan pada PSA dan emboli kira-kira 40\% meninggal. Penyebab stroke paling banyak karena hipertensi $(81,7 \%)$ dan diabetes mellitus (66,7\%).
Anamnesis adanya hipertensi hanya terdapat pada $66,7 \%$ kasus. ${ }^{3}$

Pada pasien stroke diperkirakan sekitar 50-75\% mengalami gangguan kognitif dan prevalensi menjadi demensia 3 bulan post stroke berkisar antara 23,5-61\%. ${ }^{4}$ Gangguan fungsi kognitif atau fungsi luhur yang terjadi berupa gangguan orientasi, perhatian, konsentrasi, daya ingat dan bahasa serta fungsi intelektual. ${ }^{5}$

Salah satu pemeriksaan gangguan kognitif yang digunakan ialah pemeriksaan Clock Drawing Test (CDT). Tes ini dilakukan untuk skrining kerusakan kognitif dengan sensitivitas sebesar $87 \%$ dan spesifisitas sebesar $82 \%$.

\section{METODE PENELITIAN}

Penelitian ini bersifat deskriptif dengan pendekatan potong lintang dan dilakukan pada periode November 2014 sampai Desember 2014 di Poli Neurologi RSUP Prof. Dr. R. D. Kandou. Populasi penilitian yaitu pasien post stroke yang berkonsultasi di Poli Neurologi dengan kriteria kelompok usia 35-85 tahun. Sampel ialah pasien post stroke yang memenuhi kriteria inklusi dan eksklusi dengan menggunakan teknik purposive random sampling.

Penelitian ini dilakukan dengan menggunakan data primer berdasarkan pemeriksaan langsung kepada responden Data yang diperoleh kemudian diolah, disimpulkan dan disajikan dalam bentuk grafik, tabel, dan narasi.

\section{HASIL PENELITIAN DAN BAHASAN}

Penelitian ini melibatkan 30 pasien Poli Neurologi yang memiliki riwayat stroke (post-stroke) dan yang memenuhi kriteria inklusi didapatkan responden lakilaki 15 orang (50\%) sedangkan perempuan 15 orang (50\%) yang menunjukkan jenis kelamin laki-laki dan perempuan memiliki jumlah yang sama yang mengalami gangguan kognitif khususnya gangguan 
fungsi eksekutif.

Gambaran usia pada Tabel 1 yang didapatkan terbanyak pada usia 51-65 tahun 17 responden (56,7\%) sedangkan usia 81-85 tahun tidak ditemukan. Dari data yang didapatkan, terlihat bahwa gangguan kognitif yang ditemukan lebih banyak pada kelompok usia 51-65 tahun, diikuti kelompok usia 66-80 tahun.

Penurunan fungsi kognitif dipengaruhi oleh usia. Namun, penurunan ini sangat bervariasi Ada individu yang mengalami mild cognitive impairment (gangguan kognitif ringan) pada dekade ke-5. Penelitian Salat et al. menyimpulkan terdapat perubahan volumetrik yang substansial didaerah kortikal substansia grisea dan subkortikal pada penderita nondemensia yang berusia tua serta volume substansia alba menurun dengan bertambahnya usia. ${ }^{6}$ Namun, terdapat juga individu dengan memori sangat baik pada usianya yang ke 80. Mungkin kondisi variatif ini pula yang menjadi bahan penelitian menarik di bidang neuroscience untuk menemukan hal ihwal problem utama penuaan otak. Meskipun usia mempengaruhi fungsi eksekutif namun kondisi ini sangat bervariasi dan sangat dipengaruhi oleh tingkat pendidikan individu tersebut. Semakin tinggi pendidikannya, semakin tidak rentan terhadap proses kemunduran kognitif.

\section{Karakteristik responden}

Tabel 1. Distribusi responden berdasarkan usia

\begin{tabular}{ccc}
\hline Usia & Jumlah & $\mathbf{\%}$ \\
\hline 35-50 tahun & 3 & 10 \\
51-65 tahun & 17 & 56,7 \\
66-80 tahun & 10 & 33,3 \\
81-85 tahun & 0 & 0 \\
Total & $\mathbf{3 0}$ & $\mathbf{1 0 0}$ \\
\hline
\end{tabular}

Gambaran tingkat pendidikan responden menjelaskan bahwa tingkat pendidikan SMA/Sederajat (43,3\%) memiliki posisi terbanyak dari total responden, dan pada posisi ke-2 terbanyak ialah dengan tingkat pendidikan S1 (30\%)
(Tabel 2). Hasil pemeriksaan CDT menunjukkan bahwa tingkat pendidikan $>9$ tahun lebih banyak mengalami gangguan. Hal ini dikarenakan jumlah responden yang berpendidikan $>9$ tahun (SMA/Sederajat, S1) lebih banyak daripada yang berpendidikan $\leq 9$ tahun (SD, SMP). Jika distribusi responden berdasarkan pendidikan seimbang, mungkin akan memberikan hasil yang berbeda. Berbeda dengan penelitian yang dilakukan oleh Atti AR et al. yang menemukan bahwa semakin tinggi pendidikannya, semakin tidak rentan terhadap proses kemunduran kognitif. Data dari penelitian tersebut menunjukkan bahwa pendidikan rendah, status sosial ekonomi rendah, adanya diabetes, strok, dan gejala depresi berhubungan dengan gangguan kognitif pada populasi umum.

Tabel 2. Distribusi responden berdasarkan pendidikan

\begin{tabular}{ccc}
\hline $\begin{array}{c}\text { Pendidikan } \\
\text { Terakhir }\end{array}$ & Jumlah & $\mathbf{\%}$ \\
SD & 2 & 6,7 \\
SMP & 3 & 10 \\
SMA/Sederajat & 13 & 43,3 \\
D1 & 3 & 10 \\
S1 & 9 & 30 \\
>S2 & 0 & 0 \\
Total & $\mathbf{3 0}$ & $\mathbf{1 0 0}$ \\
\hline
\end{tabular}

Gambaran distribusi responden berdasarkan pekerjaan memperlihatkan bahwa pensiunan yang terbanyak yaitu $30 \%$ dari total responden. Hasil pemeriksaan CDT menunjukkan bahwa jenis pekerjaan yang terbanyak mengalami gangguan kognitif ialah pensiunan (Tabel 3).

Tabel 3. Distribusi Responden Berdasarkan Pekerjaan

\begin{tabular}{ccc}
\hline Pekerjaan & Jumlah & \% \\
\hline Buruh/Tani & 1 & 3,3 \\
PNS & 8 & 26,7 \\
Pensiunan & 9 & 30 \\
Swasta & 7 & 23,3 \\
IRT & 5 & 16,7 \\
Total & $\mathbf{3 0}$ & $\mathbf{1 0 0}$ \\
\hline
\end{tabular}


Gambaran distribusi berdasarkan letak lesi pada otak menunjukkan bahwa responden dengan letak lesi pada hemisfer kanan (56,7\%) lebih banyak dibandingkan dengan lesi di pada hemisfer kiri (43,3\%) (Tabel 4). Dari data tersebut dapat dihubungkan dengan kerusakan hemisfer kiri dan kanan memberikan manifestasi gejala gangguan fungsi kognitif. Kerusakan hemisfer kiri akan menimbulkan gangguan kemampuan berbahasa, membaca, menulis, menghitung, memori verbal, dan gerakan motorik terampil. Kerusakan hemisfer kanan akan menimbulkan gangguan fungsi visuospasial (persepsi), visuomotor, pengabaian (neglect), memori visual, dan koordinasi motorik. ${ }^{8}$ Fungsi eksekutif dari otak dapat didefenisikan sebagai suatu proses kompleks seseorang dalam memecahkan masalah/persoalan baru. Proses ini meliputi kesadaran akan keberadaan suatu masalah, mengevaluasinya, menganalisis, serta memecahkan/ mencari jalan keluar suatu persoalan. Dalam pemeriksaaan CDT didapatkan bahwa responden dengan letak lesi baik pada hemisfer kanan maupun kiri menunjukkan adanya gangguan kognitif yang bermakna, khususnya gangguan pada fungsi eksekutif.

Tabel 4. Distribusi berdasarkan letak lesi otak

\begin{tabular}{ccc}
\hline Letak lesi otak & Jumlah (n) & $\mathbf{\%}$ \\
\hline Hemisfer Kiri & 13 & 43,3 \\
Hemisfer Kanan & 17 & 56,7 \\
Total & $\mathbf{3 0}$ & $\mathbf{1 0 0}$ \\
\hline
\end{tabular}

Gambar 1 menunjukkan 29 responden (96,7\%) dengan stroke iskemik sedangkan 1 orang (3,3\%) dengan stroke hemoragik. Gangguan fungsi eksekutif banyak dialami oleh penderita strok iskemik, adanya gangguan fungsi eksekutif berperan penting terhadap pemulihan fungsi penderita. Frekuensi gangguan kognitif pasca strok iskemik berkisar antara 20-30\%, dan makin meningkat risikonya, bahkan sampai 2 tahun pasca strok. ${ }^{9}$

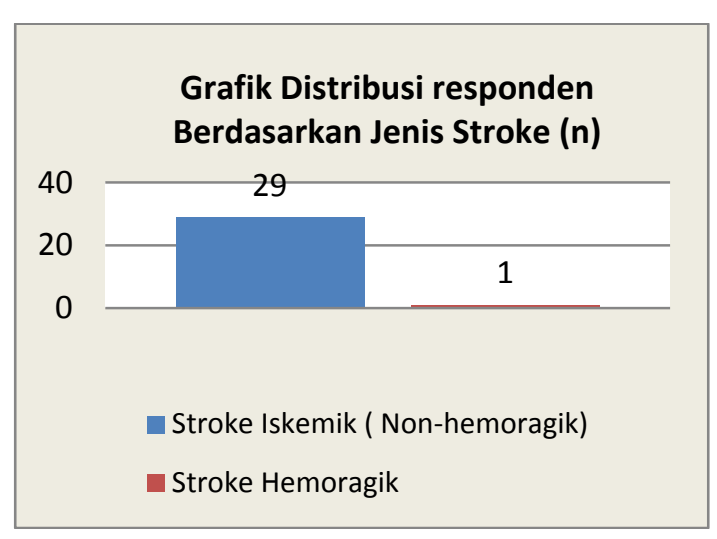

Gambar 1. Grafik distribusi berdasarkan jenis stroke

Hasil CDT (Tabel 5) menunjukan bahwa sebagian besar responden $(93,3 \%)$ mengalami gangguan kognitif lebih khusus gangguan eksekutif yang dilihat dari pemeriksaan CDT (Tabel 5). Gangguan fungsi eksekutif dapat memprediksi kurangnya kemampuan fungsi sehari-hari, dan lebih khusus ketidakmampuan untuk merawat diri sendiri sehingga memerlukan orang lain untuk membantu merawat dirinya. Skor CDT mempunyai manfaat tertentu dalam menilai kemampuan seseorang untuk hidup mandiri. ${ }^{6}$ CDT merupakan ukuran internal yang secara konsisten mudah dikelola dan menampilkan inter-rater reliability yang bagus terkait dengan nilai tes kognitif. Namun, pola CDT gagal membedakan subkelompok demensia secara klinis. ${ }^{10}$

\section{Tabel 5. Hasil Pemeriksaan CDT}

\begin{tabular}{ccc}
\hline $\begin{array}{c}\text { Hasil (sistem } \\
\text { penilaian 4 angka) }\end{array}$ & Jumlah & $\mathbf{\%}$ \\
\hline Skor 4 (Normal) & 2 & 6,7 \\
Skor 3 & 15 & 50 \\
Skor 2 & 9 & 30 \\
Skor 1 & 3 & 10 \\
Skor 0 & 1 & 3,3 \\
\hline Total & $\mathbf{3 0}$ & $\mathbf{1 0 0}$ \\
\hline
\end{tabular}

Gangguan proses eksekutif yang terjadi diakibatkan oleh terganggunya kontrol yang berhubungan dengan patologi di daerah otak prefrontal (hemisfer kiri dan hemisfer kanan). Hal ini didukung oleh 
beberapa literatur primer yang menunjukkan aktifasi pre-frontal dan komunikasi antara korteks pre-frontal dan daerahnya. Gangguan fungsi eksekutif juga diduga berkaitan dengan ganglia basal dan serebelum. $^{11}$

\section{SIMPULAN}

Berdasarkan hasil penelitian dapat disimpulkan bahwa hasil pemeriksaan CDT menunjukkan bahwa sebagian besar responden mengalami gangguan kognitif lebih khusus gangguan eksekutif.

\section{SARAN}

Perlu diadakan penelitian lebih lanjut dengan jumlah sampel lebih spesifik dan dengan tempat penelitian yang lebih luas atau bervariasi. Untuk mendapatkan hasil valid dan reliable, CDT perlu dikorelasikan dengan tes neurobehavior lain, misalnya MMSE.

CDT dapat diadministrasikan lebih mudah daripada tes yang lain, oleh karena itu perlu kiranya dibuat standarisasi CDT untuk responden Indonesia.

\section{DAFTAR PUSTAKA}

1. Auryn V. Mengenal dan Memahami Stroke. Yogyakarta: Ar-Ruzz Media Group, 2009; p.14-5; 40-1; 129-32.

2. Fieschi C, Falcou A, Sacchetti ML, Toni D. Pathogenesis, diagnosis and epidemiology of stroke. CNS Drugs;1998;9 Suppl.1:1-9.
3. Widjaja D. Stroke- Masa kini dan masa yang akan datang. 2000. [cited 2014 Oct 13]. http: //www.kalbe.co.id/files/cdk/files/13Stro ke102.pdf/13Stroke102.html.

4. Firmansyah R. Gangguan kognitif pada penderita stroke merupakan prediktor terjadinya demensia. [Laporan penelitian]. Yogyakarta: Universitas Gadjah Mada, 2007.

5. Setyopranoto I, Lamsudin R, Dahlan $P$. Peranan stroke iskhemik akut terhadap timbulnya gangguan fungsi kognitif di RSUP dr. Sardjito Yogyakarta. B. Neurosains. 2000;2;227-34.

6. Salat DH et al. Thinning of the cerebral cortex in aging. Cereb Cortex. 2008;14(7):721-30.

7. Atti AR et al. Cognitive impairment after age 60: Clinical and social correlates in the "Faenza Project" J Alzheimers Dis. 2010 Aug 6 .

8. Harsono. Kapita Selekta Neurologi (Ed. 2). Yogyakarta: Gadjah Mada University Press, 2007; p. 86-8.

9. Adam RD. Cerebrovasculer Disease. In: Principles of Neurology ( $4^{\text {th }}$ ed.). New York: Mc Graw-Hill, 2005; p. 660-740.

10. Royall DR et al. CLOX: an executive clock drawing task. J Neurol Neurosurg Psychiatry. 2004.

11. Elliot $\mathbf{R}$ et al. Prefrontal dysfunction in depressed patients performing a complex planning task: a study using positron emission tomography. Psychol Med. 2003;27:931-42. 